\title{
SPLITTING OF OPERATORS FOR FRAME INEQUALITIES
}

\author{
DONGWEI LI
}

Abstract. In this paper, we obtain some new inequalities for frames, which are parametrized by a parameter $\lambda \in \mathscr{R}$. By suitable choices of $\lambda$, one obtains the known results as special cases. Our new results also make the underlying mathematical structure that gives rise to these inequalities more transparent than previous approaches: our results show that the main point is the splitting $S=S_{1}+S_{2}$ of a positive definite frame operator $\mathrm{S}$ into the two positive semidefinite operators $S_{1}$ and $S_{2}$.

Mathematics subject classification (2010): 42C15, 47B99.

Keywords and phrases: Frames, frames operator, Hilbert space, inequalities.

\section{RE F ER ENCES}

[1] R. Balan And P. Cas AZZa And D. Edidin, On signal reconstruction without phase, Applied and Computational Harmonic Analysis, 20, 3 (2006), 345-356.

[2] R. Balan And P. Cas AZZa And D. Edidin And G. Kutyniok, Decompositions of frames and a new frame identity, Proceedings of SPIE, 5914, (2005), 1-10.

[3] R. Balan and P. Casazza and D. Edidin And G. Kutyniok, A new identity for Parseval frames, Proceedings of the American Mathematical Society, 135, 4(2007), 1007-1015.

[4] D. Donoho And E. Candes, Continuous curvelet transform: II. Discretization and frames, Applied and Computational Harmonic Analysis, 19, 2 (2005), 198-222.

[5] I. Daubechies and A. Grossmann And Y. Meyer, Painless nonorthogonal expansions, Journal of Mathematical Physics, 27, 5 (1986), 1271-1283.

[6] R. J. Duffin And A. C. Schaeffer, A class of nonharmonic Fourier series, Transactions of the American Mathematical Society, 72, 2 (1952), 341-366.

[7] Y. C. EldAR AND G. D. Forney, Optimal tight frames and quantum measurement, IEEE Transactions on Information Theory, 48, 3 (2002), 599-610.

[8] P. GĂVRUţA, On some identities and inequalities for frames in Hilbert spaces, Journal of mathematical analysis and applications, 321, 1 (2006), 469-478.

[9] D. HAN AND D. R. LARSOn, Frames, bases and group representations, American Mathematical Society, 697, 2006.

[10] J. KovaceVic ANd P. L. DRAgotTi AND V. K. GoYal, Filter bank frame expansions with erasures, IEEE Transactions on Information Theory, 48, 6 (2002), 1439-1450.

[11] S. LANG, Real and functional analysis, Springer Science and Business Media, 2012.

[12] J. LENG AND D. HAN AND T. HUANG, Optimal dual frames for communication coding with probabilistic erasures, IEEE transactions on signal processing, 59, 11 (2011), 5380-5389.

[13] D. Li And J. Leng, On Some New Inequalities For Continuous Fusion Frames in Hilbert Spaces, Mediterranean Journal of Mathematics, 15, 4 (2018), 173.

[14] D. Li AND J. LENG, On some new inequalities for fusion frames in Hilbert spaces, Mathematical Inequalities \& Applications, 20, 3 (2017), 889-900.

[15] D. Li And J. Leng And T. HuAng AND Q. GaO, Frame expansions with probabilistic erasures, Digital Signal Processing, 72, (2018), 75-82.

[16] J. Li AND Y. ZHU, Some equalities and inequalities for $\mathrm{g}$-Bessel sequences in Hilbert spaces, Applied Mathematics Letters, 25, (2012), 1601-1607.

[17] A. Poria, Some identities and inequalities for Hilbert-Schmidt frames, Mediterranean Journal of Mathematics, 14, 2 (2017), 59. 
[18] Z. XIANG, New inequalities for g-frames in Hilbert $C^{*}$-modules, Journal of Mathematical Inequalities, 10, 3 (2016), 889-897.

[19] X. ZHU AND G. WU, A note on some equalities for frames in Hilbert spaces, Applied Mathematics Letters, 23, 7 (2010), 788-790.

[20] P. ZhaO AND C. ZHAO AND P. CASAZZA, Perturbation of regular sampling in shift-invariant spaces for frames, IEEE Transactions on Information Theory, 52, 10 (2006), 4643-4648. 